\title{
Active and passive aspects of meiobenthic copepod dispersal at two sites near Mustang Island, Texas*
}

\author{
John C. Kern** \\ University of Texas Marine Science Institute, Port Aransas, Texas 78373, USA
}

\begin{abstract}
Dispersal of meiobenthic copepods was examined at 2 subtidal sites subject to moderate flow conditions, and in a laboratory experiment under conditions of no-flow. Small-scale spatial heterogeneity in settlement into containers filled with azoic sediment was found for several species in 3 field experiments. The species composition in the colonization containers was different from that observed in the surrounding sediments. Juvenile copepodites of several species were disproportionally abundant in the containers compared to the sediment, suggesting that juveniles are more likely to disperse than adults. An additional field experiment was conducted using treatments varying in food level. Several species positively responded to microbially-enriched containers, probably by a decreased emigration rate compared to that in less enriched treatments. Results of a laboratory study were similar to that in the field food-level experiment. A model is presented that depicts the roles of active and passive aspects in dispersal at these study sites.
\end{abstract}

\section{INTRODUCTION}

Dispersal is one of the most important processes for marine benthic organisms. Meiofauna, once regarded as strictly infaunal organisms, are now known to occur in large numbers in the water column in a variety of habitats (e.g. Palmer \& Gust 1985, Hicks 1986). Meiobenthic copepods, in particular, seem to be highly abundant in the water column. Dispersal of meiobenthic copepods through the water column has been shown to be much more effective than dispersal via crawling through the sediment (Chandler \& Fleeger 1983). Since dispersal is likely to be advantageous for meiofauna (see discussion in Armonies 1988a), and large numbers of meiobenthic copepods can be found in the water column, the processes of entry into, transport through, and settlement from the water column need to be better understood. The current state of

- Contribution No. 759 from the University of Texas Marine Science Institute

- Present address: Coastal Investigations Section, Louisiana Department of Wildlife \& Fisheries, PO Box 98000, Baton Rouge, Louisiana 70898-9000, USA knowledge of meiofaunal dispersal has been elegantly presented by Palmer (1988a).

The major controversy among researchers in the study of meiobenthic copepod dispersal is the relative importance of active vs passive processes in either movement from or re-entry into the sediment. Passive dispersal through entrainment from the sediment by water flow has been suggested to predominate over active behavior in high energy habitats, while active swimming from the sediment has been thought to be important in low energy areas (Palmer 1988a). However there is evidence of exceptions to this pattern. Meiobenthic copepods have been shown to have a passive dispersal mechanism in low-energy intertidal areas through sediment rafting (Hicks 1988a). On a high-energy intertidal beach in Oregon (USA) copepods displayed a large amount of active behavior by positively responding to microbially-enriched sediment (Kern \& Taghon 1986), as has also been observed in laboratory studies under conditions of no-flow (Decho \& Fleeger 1988a).

In the present study I examined the effect of sediment quality on the net colonization of meiobenthic copepods by using an experimental design that con- 
trolled for hydrodynamic influences on recruitment. Three preliminary colonization experiments were performed to examine spatial patterns of meiobenthic copepod settlement in order to improve the design of the later experiment. Additionally, species composition and population structure of copepods in containers was compared with that in ambient sediments. Significant differences could be explained by active behavior at my study area. After analysis of those preliminary studies, I performed a field colonization experiment designed to test the effect of sediment quality on the active emigration of copepods following initial settlement. Species composition and population structure differences among the different sediment treatments were also analyzed to see if different species and different population components within species behaved differently. A similar experiment was performed in the laboratory to test for active selection of different quality sediments under conditions of no-flow. The results of the field and laboratory study were then compared. Finally, predictions from a model I had previously designed to explain the dispersal process for meiobenthic copepods in moderate energy habitats were compared to the experimental results.

\section{MATERIALS AND METHODS}

September 1987 experiments. Meiobenthic copepod colonization experiments were conducted at 2 study sites near Mustang Island, Texas, USA. Both sites were shallow $(<1 \mathrm{~m})$ subtidal sandflats located in incomplete passes through the island (Corpus Cristi Pass and Packery Channel - henceforth CCP and PC, respectively), open to Corpus Cristi Bay but not connected to the Gulf of Mexico. Tidal currents are weak at these sites, but winds are usually strong and are primarily responsible for water movement. The sediment at both sites is predominantly a well-sorted, fine sand $(>97 \%)$.

On 18 September 1987, 16 colonization containers with $60 \mu \mathrm{m}$ mesh covers were set out at each of the CCP and PC sites. Colonization containers consisted of $9.7 \mathrm{~cm}$ i.d. plastic food storage containers that were $4 \mathrm{~cm}$ deep. Each container was filled with $125 \mathrm{ml}$ of defaunated sediment (ca $60 \%$ full). The sediment was previously collected from the back of a sand dune on Mustang Island and baked for $3 \mathrm{~h}$ at $200^{\circ} \mathrm{C}$. The experimental sediment was visually similar to that found ambiently at the study sites. Four containers were anchored on top of the sediment surface with each container placed within ca $25 \mathrm{~cm}$ from adjacent containers, at each of 4 locations laid out $4 \mathrm{~m}$ from neighboring colonization locations. The covers were removed shortly before sunset. After sunrise on 19
September, the containers were reclosed after being open ca $13 \mathrm{~h}$ at the PC site and $16 \mathrm{~h}$ at the CCP site. Winds were strong when the containers were set out and a cold front came through the area during the evening, changing the wind direction and increasing its strength. Sixty sediment cores $(2.0 \mathrm{~cm}$ i.d.) were taken down to $3 \mathrm{~cm}$ (ca $2 \mathrm{~cm}$ below the surficial oxidized layer) at both the CCP and PC study sites to obtain an estimate of ambient meiobenthic copepod abundance and population structure.

After collection all sediment from each colonization container was quantitatively transferred into individual storage containers. Samples were preserved with a formalin-seawater solution (ca 10\%, filtered through a $63 \mu \mathrm{m}$ screen) and stained with Rose Bengal. Later, meiobenthic copepods were extracted from the sediment with a swirl/decant technique (modified from Wieser 1960) and retained on a $63 \mu \mathrm{m}$ sieve. Five decantations were used. In an earlier study with similarly large-volume samples (Kern \& Taghon 1986), I achieved an extraction efficiency of over $99 \%$ using this method. Two samples from the present study were completely examined, and no copepods remained with the sediment following extraction. Sediment core samples were treated similarly, except that only 3 decantations were used.

Sorting was performed using a dissecting microscope at $25 \times$. Copepods were later examined with a dissecting microscope at $75 x$, and, if necessary, a compound microscope at 100 to $400 \times$ Adults were sexed, and identified to species when practical. Two species of Halicyclops are found in my study sites, but are not easily separable. Dissections suggest that Halicyclops fosteri Wilson is rare, and a second unidentified species is very common. All Halicyclops individuals were grouped at the genus level for all analyses in all experiments. Juvenile copepodites (CI to CV) were identified to species when they were distinct enough for reasonable separation.

One-way ANOVA's were used to test for differences in colonization among the 4 treatment locations at each sampling site. Untransformed data were used since variances were homogeneous among the sampling locations ( $F_{\max }$ test). When the result of an ANOVA was significant at the $p<0.05$ level, differences in mean abundance among locations were examined using Duncan's New Multiple Range Test (Steel \& Torrie 1980). The 4 most abundant species in the ambient cores were used to look for differences in the species composition between ambient sediments and the colonization containers. The distribution of abundance of these 4 species in the sediment was tested against that in the colonization containers using a Test of Independence (Sokal \& Rohlf 1981). When less than 5 individuals of a species occurred in either 
the sediment or the containers, classes were lumped as recommended (Sokal \& Rohlf 1981). Lastly, Tests of Independence were used to test whether the population structure (females:males:juvenile copepodites) in colonization containers was similar to that in ambient sediments. This test was performed only on those species for which copepodites could be distinguished, and which were abundant enough in both sample types to allow analysis. If adult females were rare, males and females were lumped and contrasted against juvenile copepodites.

December 1987 experiment. On 5 December 1987 a new colonization experiment was conducted at the PC site. There were 2 major differences between this experiment and the September experiments. First, the number of treatment locations was increased from 4 to 6. Second, only 30 sediment cores were taken to estimate ambient abundance and these cores were taken prior to opening the containers. The mesh covers were removed shortly after sunset and reclosed after $12.5 \mathrm{~h}$, following sunrise on 6 December. Winds were strong during this period and from a constant direction. Sample processing and statistical analyses followed those of the September experiments.

Field food-level experiments. Sediment food levels were manipulated by culturing benthic algae and bacteria on sediment in colonization containers for varying lengths of time. Containers with $75 \mathrm{ml}$ of cleaned sediment were placed in $50 \mathrm{l}$ aquaria that were partially filled with 40 um-filtered seawater so that the water level was ca $5 \mathrm{~cm}$ above the tops of the containers. The containers were less than half full with ca $2.2 \mathrm{~cm}$ between the surface of the sediment and the top of the containers. The water was replaced each day and the containers were kept on a $12 \mathrm{~h}$ on to $12 \mathrm{~h}$ off light regime. Separate aquaria were used for each food level. Containers were cultured for 35, 20, and $5 \mathrm{~d}$ and will henceforth be referred to as High, Moderate, and Low treatments, respectively. A fourth food treatment, called None, consisted of containers filled with 5 umfiltered seawater and kept in the dark $1 \mathrm{~d}$ prior to deployment in the field. Two containers from the High treatment were sacrificed for examination of contamination by meiobenthic copepods before deployment. No copepods were found, although a few small nematodes and turbellarians were present.

A relative measure of food levels in these treatments was obtained by taking cores for sediment chlorophyll a analysis. Samples of $2 \mathrm{~cm}^{3}$ of sediment were taken from each side of 2 sacrificed containers for each treatment immediately before containers were brought out to the field. The samples were kept frozen in the dark prior to extraction in $10 \mathrm{ml}$ of acetone, and chlorophyll a was measured on a Turner Model 10 Fluorometer.

On 16 April 1988 the containers were placed subti- dally at the CCP site. The arrangement used was similar to that in the earlier experiments. One container from each treatment was placed at each of 7 locations and each location was $4 \mathrm{~m}$ from adjacent locations. Containers were placed on the sediment surface with tops on and left undisturbed for $1 \mathrm{~h}$ to equilibrate. The covers were removed prior to sunset and replaced after sunrise 14 h later Five sediment cores were taken at each of the treatment locations for ambient copepod estimation. Six sets of chlorophyll samples were taken from the surrounding area for comparison with chlorophyll levels in the treatments.

Differences in colonization of food treatments by meiobenthic copepods was analyzed using a Randomized Complete Block. ANOVA, using sample location as a block. Differences in species composition among the 4 food treatments were analyzed using the 7 most abundant species in a Test of Independence. For abundant species with identifiable copepodites, population structure differences among food treatments were assessed using Tests of Independence. A Nested ANOVA was used to compare chlorophyll levels among ambient sediments and the None through High treatments

Laboratory food-level experiment. Colonization containers were cultured as in the field experiment, except that $150 \mathrm{ml}$ of sediment was used. Three treatments were used; the High treatment was cultured for $30 \mathrm{~d}$ and a Low treatment for $6 \mathrm{~d}$. The third treatment was identical to the None treatment earlier. Cores for chlorophyll a analysis were taken, but improperly handled, preventing estimation of the chlorophyll levels in the 3 treatments.

Three containers, one from each treatment, were placed in each end of three $50 \mathrm{l}$ aquaria filled to $10 \mathrm{~cm}$ depth on 5 May 1988. Meiobenthic copepods were collected from the CCP site using $10 \mathrm{~cm}$ i.d. cores, anaesthetized in a $\mathrm{MgCl}_{2}$ solution, and separated from the sediment by decantation onto a $40 \mu \mathrm{m}$ sieve. The copepods, concentrated to ca 5 times ambient density, were placed in empty colonization containers, the tops were closed and 1 container placed at the center of each tank. After $1 \mathrm{~h}$ the tops were removed. The aquaria were left undisturbed for $24 \mathrm{~h}$ (8.5 h light to $12 \mathrm{~h}$ dark to $3.5 \mathrm{~h}$ light). The treatment containers and the center container were closed and the copepods extracted. Water remaining in each aquarium was siphoned onto a $40 \mu \mathrm{m}$ sieve to collect the copepods remaining out of colonization containers.

Comparison of colonization of the food treatments was performed with an ANOVA, blocking by aquarium. The 2 containers of each treatment in an aquarium were treated as simple replicates. Species composition and population structure comparisons were not made. 


\section{RESULTS}

\section{Preliminary colonization experiments}

Significant spatial differences in mean copepod abundance in colonization containers were found in all 3 initial field experiments (Table 1). At the CCP study site 5 of 7 taxa abundant enough to merit statistical analysis displayed a significant degree of spatial heterogeneity in settlement (Fig. 1). Three of 6 taxa tested from the PC site in September displayed significant levels of heterogeneity in settlement (Fig. 2). Significant levels of spatial heterogeneity in settlement was observed for 2 of 5 taxa evaluated at the PC site in December (Fig. 3). Overall many of the species showed great variability in settlement on spatial scales of a few meters, but relatively little variation among replicate colonization containers placed close together at a single location. Some organic detritus was found in the colonization containers showing that they were acting as depositional environments.

The species composition of copepods in the colonization containers in these experiments was dramatically different from that in surrounding sediment in all 3

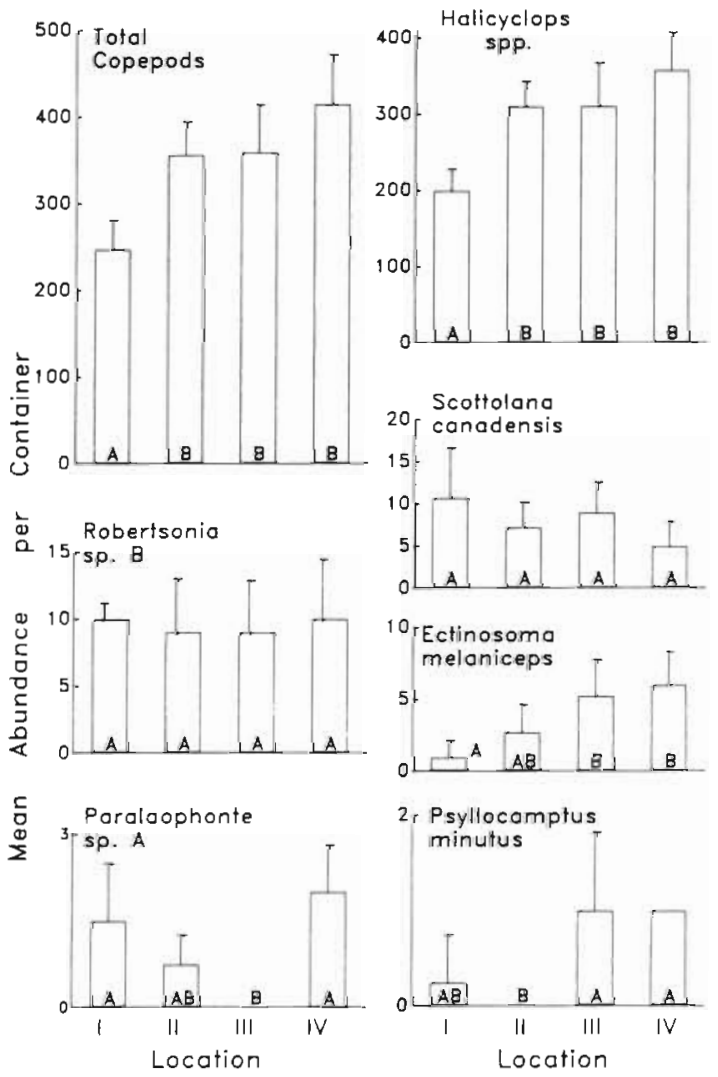

Fig. 1. Mean abundance (+1 SD) of total copepods and of abundant species in colonization containers at treatment locations from CCP site in September 1987 Locations with same letter do not differ significantly in mean abundance
Table 1 Summary of results of ANOVA's comparing settlement into containers among treatment locations in the 3 initial field experiments. NS: not significant at $\alpha=0.05$ level

\begin{tabular}{|c|c|c|}
\hline Taxon & F-value & $\begin{array}{c}\text { Significance } \\
\text { level }\end{array}$ \\
\hline \multicolumn{3}{|l|}{ CCP, September $(\mathrm{d} \hat{\mathrm{i}}=3,12)$} \\
\hline Total copepods & 8.981 & 0.0022 \\
\hline Halicyclops spp. & 9.742 & 0.0015 \\
\hline Scottolana canadensis & 1.514 & NS \\
\hline Ectinosoma melaniceps & 5.131 & 0.0164 \\
\hline Robertsonia sp. B & 0.091 & NS \\
\hline Paralaophonte sp. A & 6.391 & 0.0078 \\
\hline Psyllocamptus minutus Sars & 4.636 & 0.0225 \\
\hline \multicolumn{3}{|l|}{ PC, September $(\mathrm{df}=3,12)$} \\
\hline Total copepods & 12.698 & 0.0005 \\
\hline Halicyclops spp. & 24.719 & 0.0001 \\
\hline Zausodes arenicolus & 3.305 & NS \\
\hline Ameira parvula & 5.415 & 0.0137 \\
\hline Scotlolana canadensis & 1.112 & NS \\
\hline Ectinosoma melaniceps & 0.204 & NS \\
\hline \multicolumn{3}{|l|}{ PC, December $(\mathrm{df}=5,18)$} \\
\hline Total copepods & 9.009 & 0.0002 \\
\hline Halicyclops spp. & 3.333 & 0.0264 \\
\hline Zausodes arenicolus & 1.800 & NS \\
\hline Ameira parvula & 1.422 & NS \\
\hline Paradactylopodia brevicornis & 2.491 & NS \\
\hline
\end{tabular}
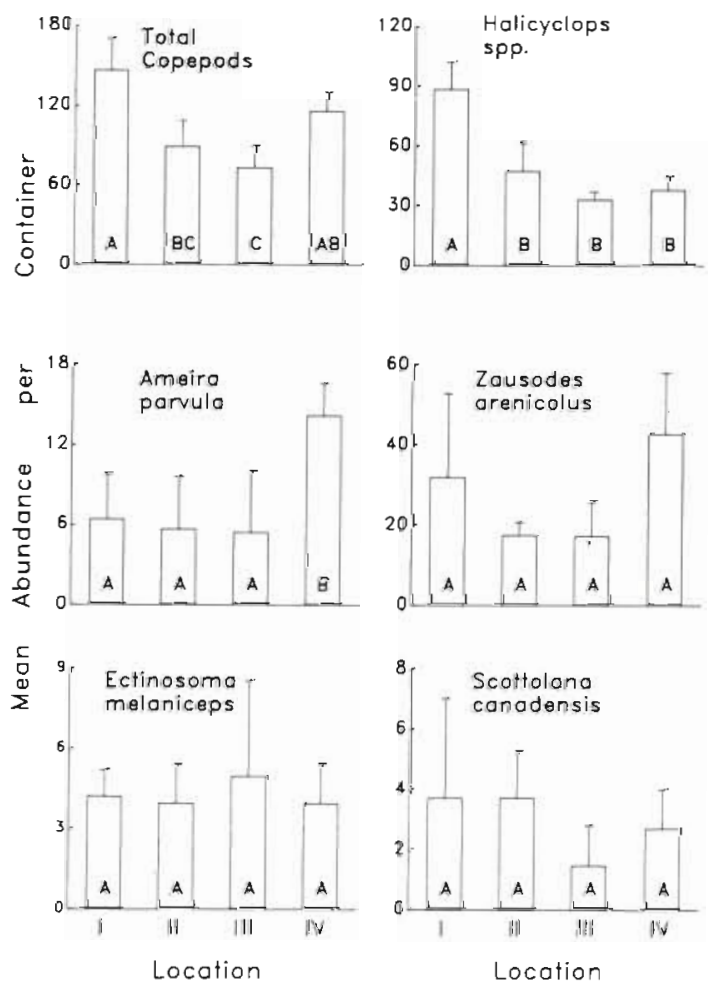

Fig. 2. Mean abundance (+1 SD) of total copepods and of abundant species in colonization containers at treatment locations from PC site in September 1987 Locations with same letter do not differ significantly in mean abundance 
Fig. 3. Mean abundance (+1 SD) of total copepods and of abundant species in colonization containers at treatment locations from PC site in December 1987. Locations with same letter do not differ significantly in mean abundance
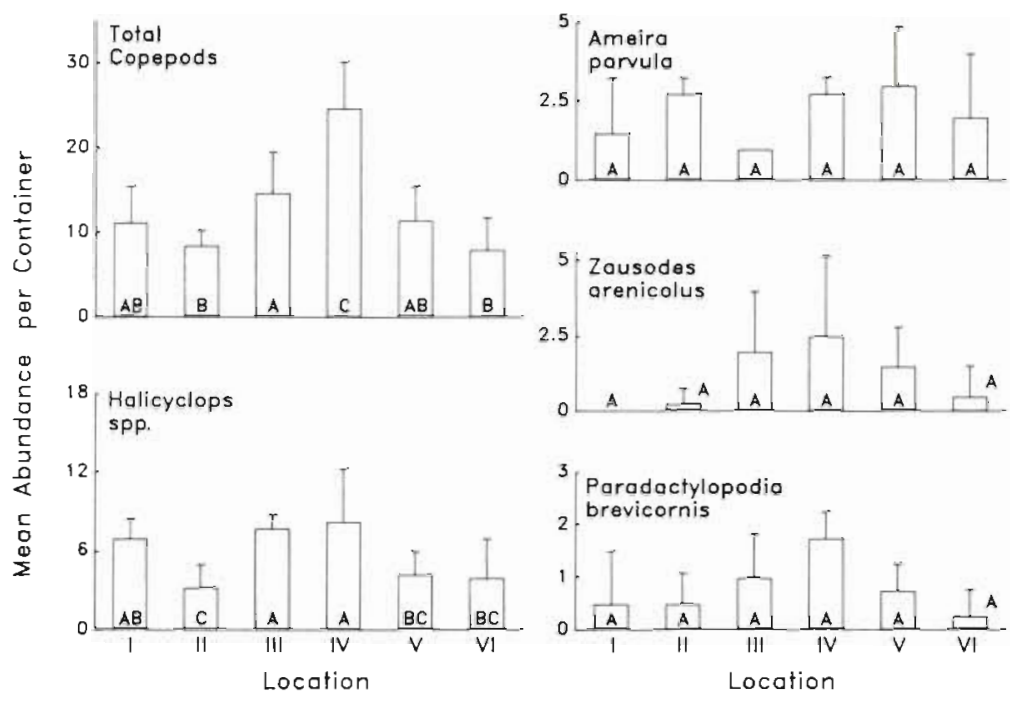

3 Paradactylopodio 2. brevicornis

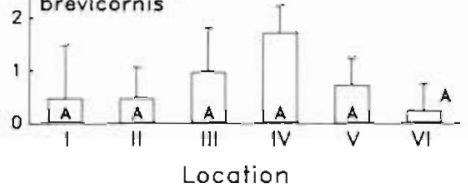

experiments (Fig. 4). In September at the CCP site, Halicyclops spp., Scottolana canadensis (Willey), Nitocra sp. A, and Robertsonia sp. B were the 4 dominant sediment species. There was a highly significant difference in the distribution of these 4 species between the ambient sediment and the colonization containers $(G=443 ; p \ll 0.005)$. The fourth most abundant container species, Ectinosma melaniceps Boeck, was not found in any sediment cores. Similarly dramatic differences in species composition were found at the PC site in September and December. In September the 4 most

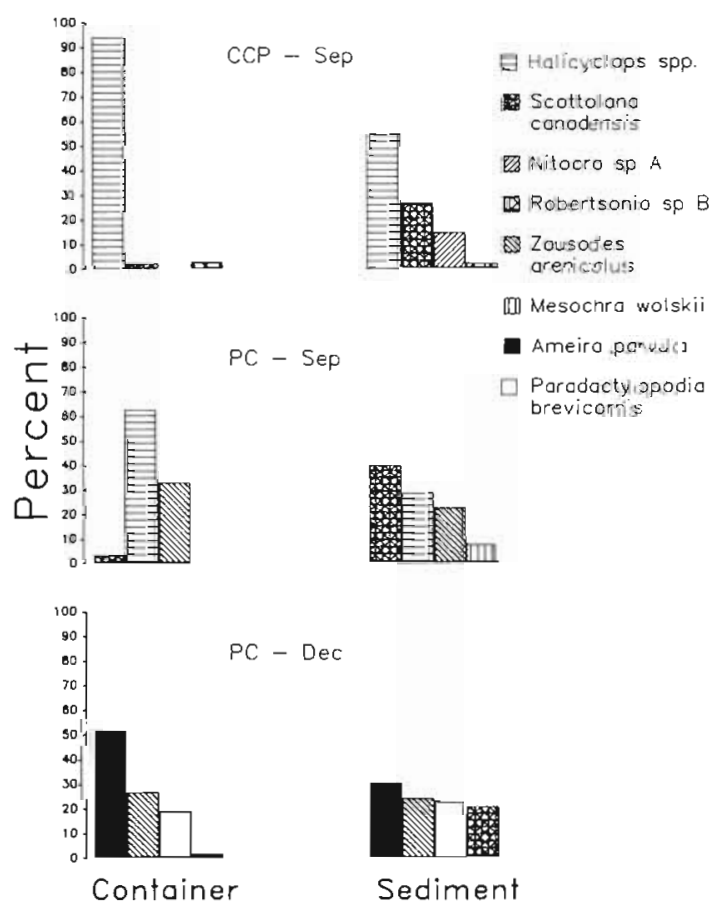

Fig. 4. Percent composition of 4 most abundant sediment copepods from the 3 initial field experiments in colonization containers and ambient sediment abundant sediment species, S. canadensis, Halicyclops spp., Zausodes arenicolus Wilson, and Mesochra wolskii Jakubisiak, were distributed differently between the containers and the sediment $\mathrm{lG}=265$; $p \ll 0.005$ ). E. melaniceps was the fourth most common copepod identified from colonization containers and was again not found in sediment cores. In December ambient sediment at the PC site was dominated by Ameira parvula (Claus), $Z$. arenicolus, Paradactylopodia brevicornis (Claus), and $S$. canadensis. Again these species were not distributed similarly in the containers and the sediment $(\mathrm{G}=20.8 ; \mathrm{p}<0.005)$. Halicyclops spp. was the most abundant copepod in the colonization containers ( $43.8 \%$ ), yet it comprised only $5.3 \%$ of the copepods found in sediment cores.

Population structure differences between ambient sediment and colonization container copepods were assessed for 4 species. Significant differences were found in 7 of 8 tests performed (Table 2). Zausodes arenicolus at the $\mathrm{PC}$ site in December had similar population structures in both the sediment and in the containers (Fig. 5F). Ameira parvula juveniles were proportionally more abundant in ambient sediment than in colonization containers, while adult males displayed the opposite trend (Fig. $5 \mathrm{H}$ ). Juvenile copepodites for the remaining species examined were all disproportionally abundant in the colonization containers (Fig. 5A to E, G). None of the remaining species whose copepodites could be identified were abundant enough in both sample types to merit statistical analysis.

\section{Field food experiment}

Significantly different levels of chlorophyll a were established in the food-level treatments $(p<0.0001)$. The None and Low treatments had mean chlorophyll a 
Table 2. Summary of Test of Independence results comparing population structures between different treatments for all field experiments. NS: not significant at $\alpha=0.05$ level

\begin{tabular}{|c|c|c|c|c|c|}
\hline $\begin{array}{l}\text { Site } \\
\text { Date }\end{array}$ & Comparisons made & Species & $\begin{array}{l}\text { Population } \\
\text { components used }\end{array}$ & $\begin{array}{l}\text { G-value } \\
\text { (df) }\end{array}$ & Significance \\
\hline \multirow[t]{3}{*}{$\begin{array}{l}\text { PC } \\
\text { Sep }\end{array}$} & \multirow[t]{3}{*}{$\begin{array}{l}\text { Between ambient sedi- } \\
\text { ments and containers }\end{array}$} & Scottolana canadensis & Adults, juveniles & $\begin{array}{l}8.5 \\
(1)\end{array}$ & 0.005 \\
\hline & & Zausodes arenicolus & Females, males, juveniles & $\begin{array}{l}1.6 \\
(2)\end{array}$ & NS \\
\hline & & Halicyclops spp. & Females, males, juveniles & $\begin{array}{l}16.5 \\
(2)\end{array}$ & 0.005 \\
\hline \multirow[t]{2}{*}{$\begin{array}{l}\text { CCP } \\
\text { Sep }\end{array}$} & \multirow[t]{2}{*}{$\begin{array}{l}\text { Between ambient sedi- } \\
\text { ments and containers }\end{array}$} & Scottolana canadensis & Adults, juveniles & $\begin{array}{l}15.6 \\
(1)\end{array}$ & 0.005 \\
\hline & & Halicyclops spp. & Females, males, juveniles & $\begin{array}{c}64.2 \\
(2)\end{array}$ & 0.005 \\
\hline \multirow[t]{3}{*}{$\begin{array}{l}\text { PC } \\
\text { Dec }\end{array}$} & \multirow[t]{3}{*}{$\begin{array}{l}\text { Between ambient sedi- } \\
\text { ments and containers }\end{array}$} & Zausodes arenicolus & Adults, juveniles & $\begin{array}{l}7.6 \\
(1)\end{array}$ & 0.01 \\
\hline & & Halicyclops spp. & Females, males, juveniles & $\begin{array}{l}6.2 \\
(2)\end{array}$ & 0.05 \\
\hline & & Ameira parvula & Females, males, juveniles & $\begin{array}{c}27.3 \\
(2)\end{array}$ & 0.005 \\
\hline \multirow[t]{4}{*}{$\begin{array}{l}\text { CCP } \\
\text { Apr }\end{array}$} & \multirow[t]{4}{*}{$\begin{array}{l}\text { Among containers differ- } \\
\text { ing in chlorophyll level }\end{array}$} & Scottolana canadensis & Females, males, juveniles & $\begin{array}{c}14.8 \\
(6)\end{array}$ & 0.025 \\
\hline & & Zausodes arenicolus & Females, males, juveniles & $\begin{array}{l}6.6 \\
(6)\end{array}$ & NS \\
\hline & & Halicyclops spp. & Females, males, juveniles & $\begin{array}{l}9.8 \\
(6)\end{array}$ & NS \\
\hline & & Ectinosoma melaniceps & Females, males, juveniles & $\begin{array}{l}2.1 \\
(6)\end{array}$ & NS \\
\hline
\end{tabular}
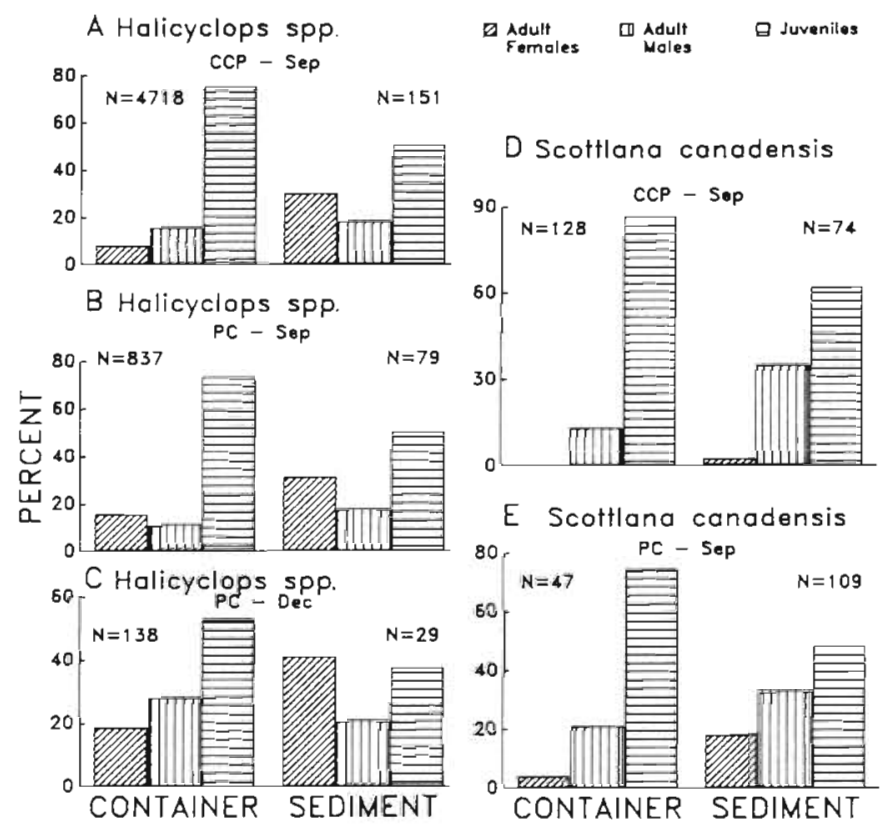

F Zausodes arenicolus
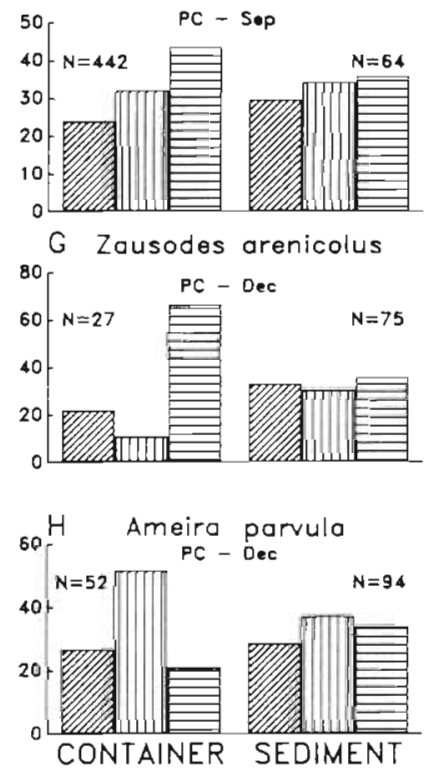

Fig 5. Population structure of select copepod species from the 3 initial field expenments in ambient sediment and in colonization containers 

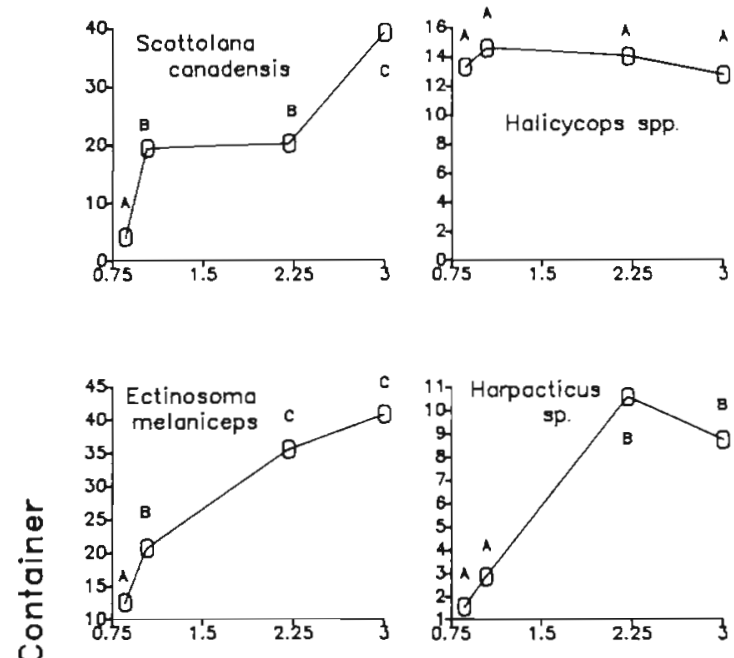

(1)
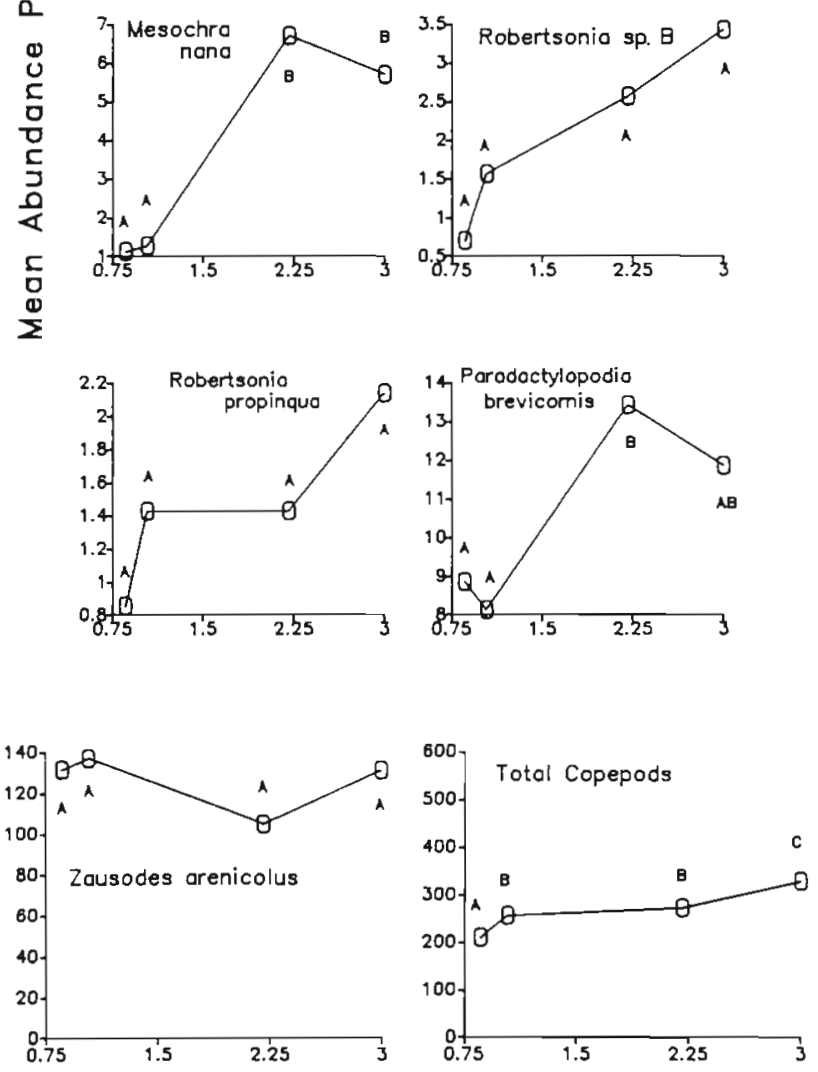

\section{Log Initial Chlorophyll Level}

Fig. 6. Mean abundance of total copepods and of abundant species in treatment containers differing in food (chlorophyll) level. Treatments with same letter do not differ significantly in mean abundance

levels of 7.3 and $10.95 \mu \mathrm{g} \mathrm{cm}^{-2}$, respectivly. The Moderate treatment was significantly higher at $160.37 \mu \mathrm{g}$ $\mathrm{cm}^{-2}$. Chlorophyll a levels in the ambient sediment were signicantly higher than the Moderate treatment
Table 3. Summary of results of RCB ANOVA's comparing abundance of meiobenthic copepods among the 4 food treatments in the field experiment. NS: not significant at the $\alpha=$ 0.05 level; $\mathrm{df}=6,18$ for Area effect; 3,18 for Food effect

\begin{tabular}{|c|c|c|c|}
\hline Taxon & Source & F-value & $\begin{array}{l}\text { Signifi- } \\
\text { cance }\end{array}$ \\
\hline Total & Area & 4.39 & 0.0066 \\
\hline copepods & Food & 13.96 & 0.0001 \\
\hline Zausodes & Area & 1.94 & NS \\
\hline arenicolus & Food & 1.95 & NS \\
\hline Scottolana & Area & 0.92 & NS \\
\hline canadensis & Food & 19.75 & 0.0001 \\
\hline Ectinosoma & Area & 0.91 & NS \\
\hline melaniceps & Food & 26.76 & 0.0001 \\
\hline Harpacticus & Area & 0.73 & NS \\
\hline $\mathrm{sp}$ & Food & 6.39 & 0.0039 \\
\hline Halicyclops & Area & 2.42 & NS \\
\hline spp. & Food & 0.15 & NS \\
\hline Paradactylopodia & Area & 1.72 & NS \\
\hline brevicornis & Food & 3.87 & 0.0039 \\
\hline Mesochra & Area & 2.88 & 0.0377 \\
\hline nana & Food & 11.11 & 0.0002 \\
\hline Robertsonia & Area & 1.96 & NS \\
\hline sp. B & Food & 2.04 & NS \\
\hline Robertsonia & Area & 1.03 & NS \\
\hline propinqua (T. Scott) & Food & 0.88 & NS \\
\hline
\end{tabular}

at $936.06 \mu \mathrm{g} \mathrm{cm}^{-2}$, but indistinguishable from the High treatment $\left(993.60 \mu \mathrm{g} \mathrm{cm}{ }^{-2}\right)$.

Great differences in colonization were found for some meiobenthic copepods among food treatments (Fig. 6). Six of 10 taxa abundant enough to merit analysis displayed statistically significant differences in abundance among food treatments (Table 3). The most selective species were Scottolana canadensis, ECtinosoma melaniceps, Harpacticus sp., and Mesochra nana Brady. Zausodes arenicolus, by far the dominant species collected in the treatment containers $(\mathrm{n}=3534$; over $45 \%$ of container copepods), appeared to be indifferent to the food treatments used in the study. Despite the dominance by $Z$. arenicolus, total copepods differed significantly in abundance among the treatments. Some rare copepods whose responses were not tested due to their low abundance seemed to differentiate among the treatments. For example, half of all Paralaophonte sp. $(n=26)$ and Tegastidae individuals $(\mathrm{n}=8)$ were found in the High treatment. Metis sp. individuals $(\mathrm{n}=15)$ were not found in any of the None treatment containers, but were found in 


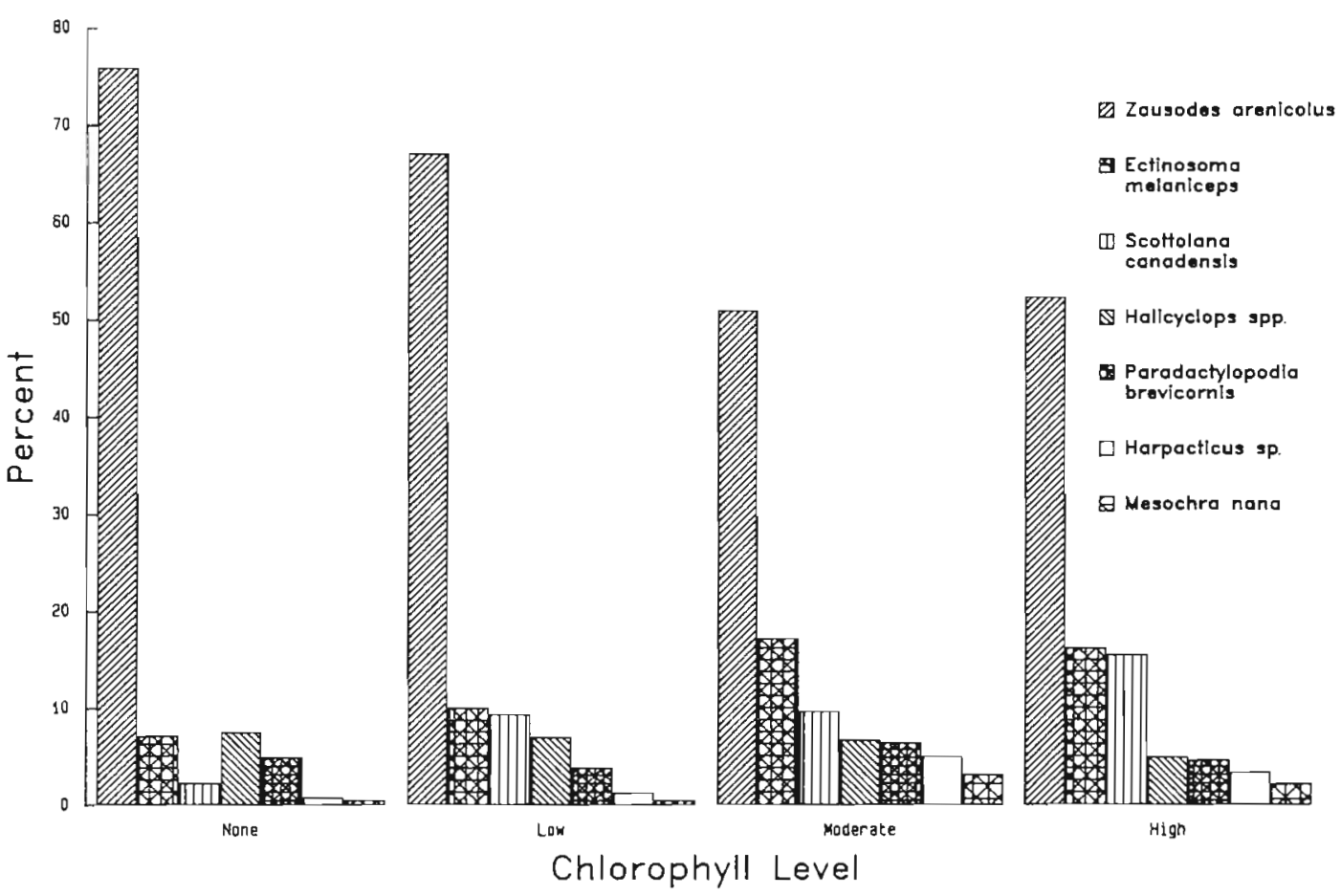

Fig. 7 Percent composition of 7 most abundant copepod species in treatment containers in field food-level experiment

approximately equal numbers in the remaining treatments

The copepod species composition found among the 4 food levels differed greatly (Fig. 7). The proportions of the top 7 species collected in the experiment were significantly different among the treatments $(G=444$ i $p \ll 0.005)$. Zausodes arenicolus made up over $75 \%$ of these 7 species in the None treatment, and just over
$50 \%$ in the Moderate and High treatments. The relative percentage of Ectinosoma melaniceps, Harpacticus sp. and Mesochra nana in the Moderate and High treatments were each over twice as great as their proportion in the None treatment. The difference was even greater for Scottolana canadensis. This species represented just over $2 \%$ of the selected copepods in the None treatment but its contribution rose to over $15 \%$ in

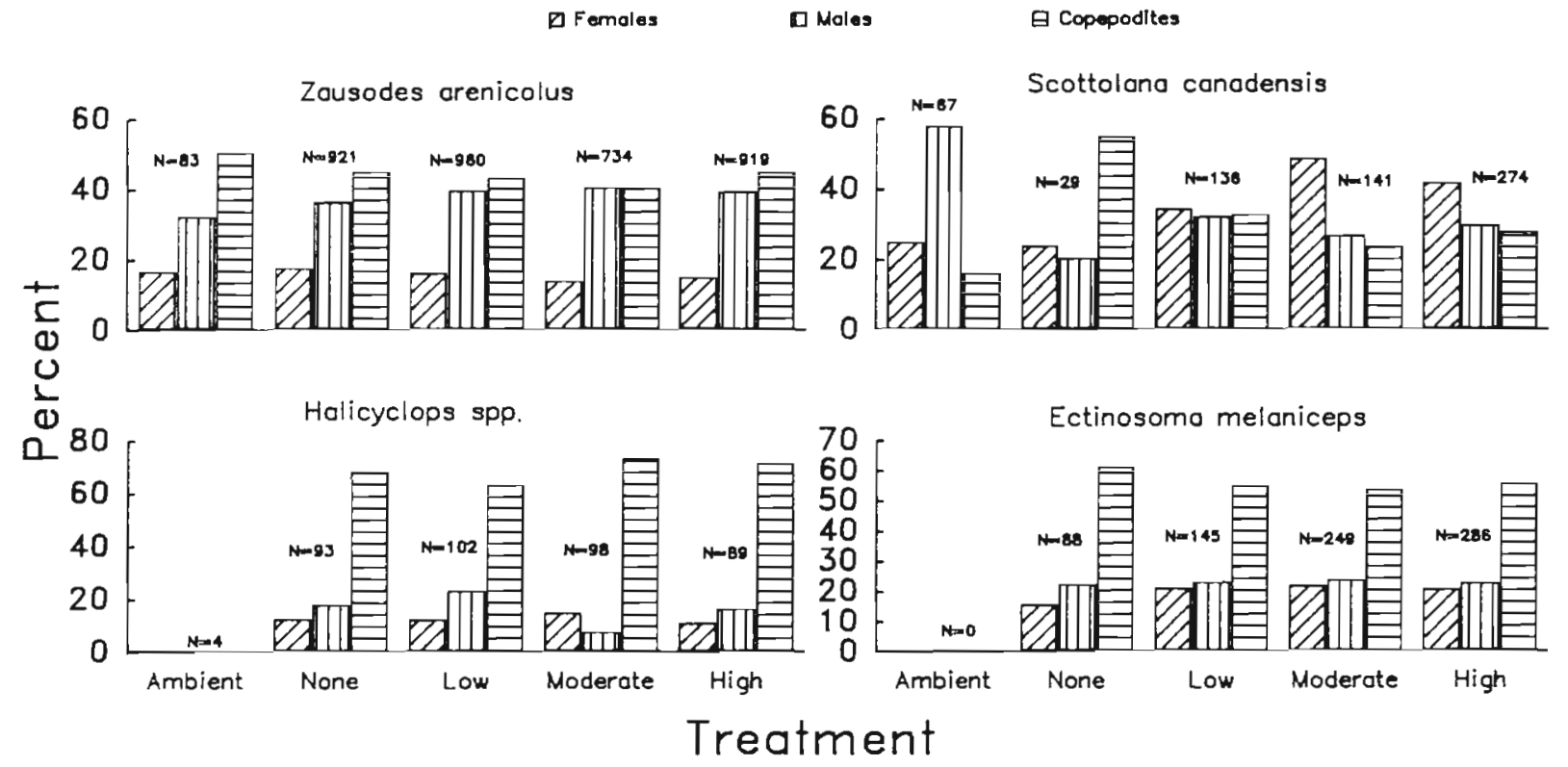

Fig. 8. Population structure of selected copepod species in ambient sediment and treatment containers from the field food-level experiment 
the High treatment. Unlike most other species, $S$. canadensis appeared to be highly selective between the None and Low treatments (Fig. 7).

Copepod population structures were similar among the 4 food treatments for 3 of 4 species tested (Fig. 8). Scottolana canadensis populations did differ among the treatments (Table 2). Adult $S$. canadensis females were the dominant component in both High and Moderate food treatments, but a relatively minor component of the population in the None treatment. In Low treatment containers females, males, and juveniles made up approximately equal proportions of the population in contrast to the None treatment where juveniles represented over $50 \%$ of all S. canadensis individuals.

\section{Laboratory food experiment}

Scottolana canadensis $(\mathrm{n}=91)$ and Zausodes arenicolus $(\mathrm{n}=186$ ) were the only 2 copepods abundant enough in the treatment containers to merit statistical analysis. S. canadensis abundance differed significantly among the food treatments $(F=20.8 ; p<0.0001)$. Abundance in the None treatment was lower than in the Low and High treatments, which were indistinguishable (Fig. 9). Z. arenicolus, which made up over $50 \%$ of all copepods found in the treatment containers did not show any trends with respect to the treatments used. Total copepods, not surprisingly, also did not differ significantly among the treatments.

There were noticeable differences in the behavior of the copepod species introduced to the aquaria. Less than $20 \%$ of $Z$. arenicolus individuals were found in the original containers placed in the aquaria at the start of the experiment. The remaining $Z$. arenicolus individuals were either in the treatment containers or were found in the water drained out of the aquaria after all containers had been removed. Halicyclops spp. also was very active in leaving the original containers $(80.8 \%)$, although few colonized the treatment containers. In contrast, Scottolana canadensis tended to remain in the containers in which they were introduced to the tanks (79.7\%). Over $70 \%$ of those S. canadensis individuals that did swim out of the original containers colonized treatment containers. All 18 Cletocamptus albuquerquensis (Herrick) individuals remained in the original containers, suggesting that this species is a poor disperser.

\section{DISCUSSION}

It is clear from the results of the preliminary field colonization studies that small-scale spatial heterogeneity in settlement requires consideration in studies
Tank 1

Fig. 9. Abundance of total copepods, Zausodes arenicolus, and Scottolana canadensis in replicate containers from each of the aquaria in the laboratory food-level experiment

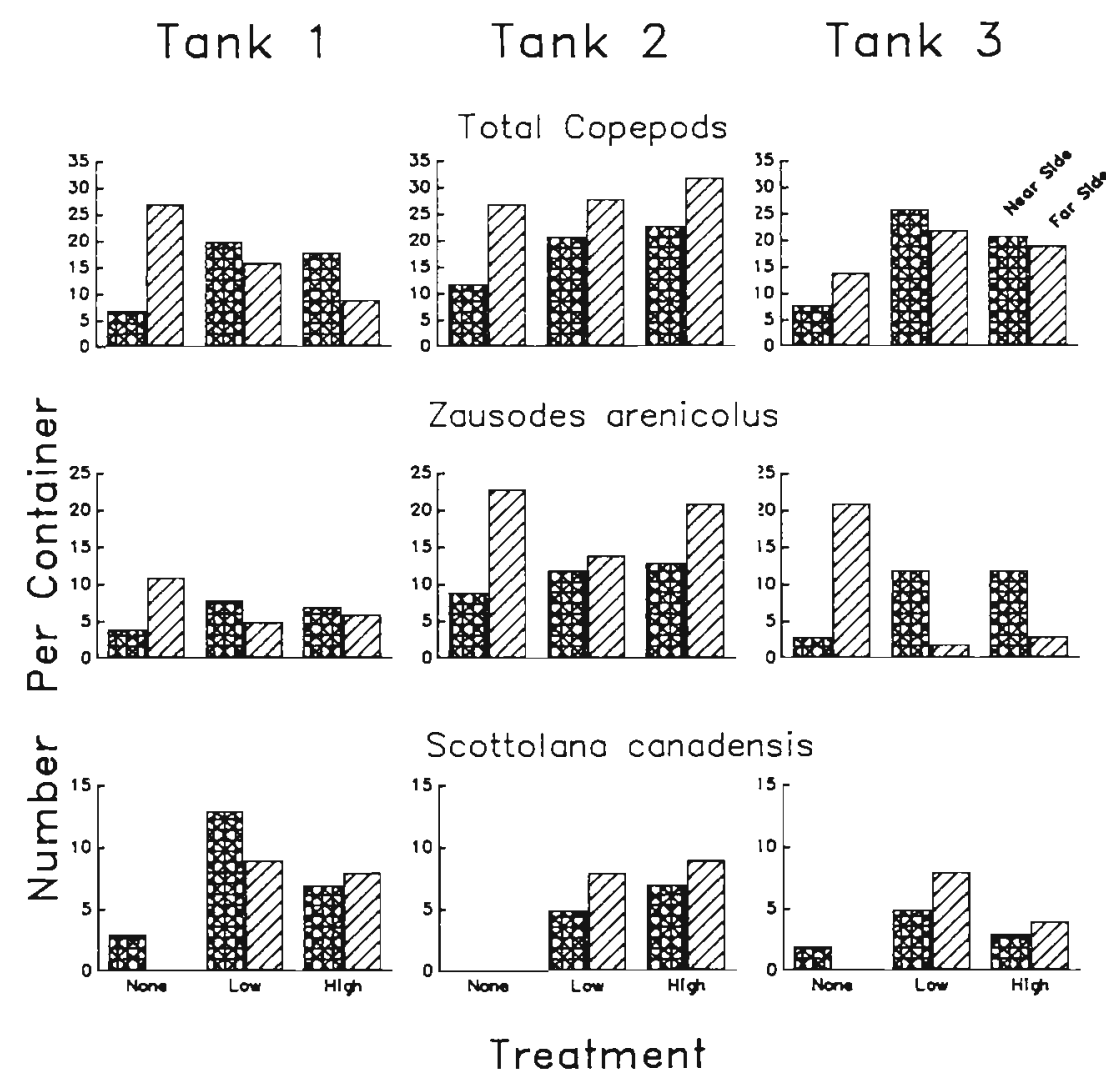


of meiobenthic copepod dispersal. The study areas chosen had no apparent epibenthic structures in the immediate experimental sites to influence local flow conditions. The arrangement of containers and the sediment used in them was identical at each site. Despite these conditions heterogeneity was found. Spatial differences in copepod settlement in the colonization containers may have been due to subtle differences in flow conditions on scales of a few meters and/or of differences in the abundance of potential recruits in the water column on the same spatial scales.

In the field food-level experiments the deployment of all treatments at each location and the utilization of a block design ANOVA, treating separate areas as blocks, proved adequate to detect differences in settlement among the treatments. The results were often so highly significant that the use of a purely random design would probably have been sufficient to demonstrate significant differences in settlement, even without the reduction in the experimental error term that was possible through use of the block design. But in other experiments looking for more subtle influences on recruitment, lack of control of spatial differences in settlement might affect the results. Interpretation of results from experiments which ignore the potential effects of spatial heterogeneity in settlement (e.g. Eckman 1983) becomes problematic

The differences observed in species composition between ambient sediment and the colonization containers in the preliminary study suggest that active behavior is important in dispersal of meiobenthic copepods in the study area. A purely passive mechanism of suspension and deposition would be expected to result in similar species composition in both ambient sediment and the containers unless my copepods were transported from different habitats as has been observed elsewhere (Palmer \& Gust 1985). The restricted topography of the 2 passes I used as study sites, and the similarity of the sediment throughout them, suggests that transport from different habitats was not important in producing my results. Additionally, all species collected in containers in these experiments have been collected in sediment cores taken at these passes on other occasions (Kern unpubl.). The dramatic difference in faunal composition may be explained by behavioral differences among species (see discussion in Chandler \& Fleeger 1983). Alternative explanations supporting a passive model include that differences in morphology among species may influence the rate at which they were 'collected' by the colonization containers, and differences in their susceptibility to being entrained by flow. However in light of the species composition found among colonization containers containing different sediment treatments in the food colonization experiment, and the differences in behavior observed in the laboratory study, these alternative explanations do not appear sufficent to explain the differences observed.

Intra-specific differences between sediment and container copepods also support the importance of behavior in dispersal. In 6 of 8 cases examined, juveniles appeared to be more active dispersers than did adults (Fig. 5). This also appears to have been true for Scottolana canadensis in the field food-level experiment if the ambient sediment population is compared to that found in the None treatment (Fig. 8), although this comparison was intentionally not tested. If passive erosion and settlement processes were predominate in copepod dispersal it is unlikely that there would have been such dramatic differences in population structure between container and sediment samples. Few previous studies have looked for ontogenetic differences in copepod behavior. In one such study, higher initial recolonization of a defaunated sediment patch by juvenile copepodites of Zausodes arenicolus and Paradactylopodia brevicornis was observed (Kern \& Bell 1984). Adult females were the poorest colonizers in that study. In another study, juvenile copepodites of Pseudobradya beduina were found in the overlying water in great numbers while adults were found in the sediment (Huys et al. 1986). Juvenile copepodites might generally be more active dispersers than are adults, especially females

Differences in net copepod settlement among the treatments used in the field food-level study provide the strongest support for a predominant role of active behavior in dispersal of copepods at the CCP site. The results obtained cannot be easily used to support a strong role for passive dispersal. It is likely that initial settlement into the containers was largely a process of being passively deposited into the containers. This is because of the strong winds producing appreciable water movement in the shallow study-area, and the containers being intended as depositional environments located above the sediment surface. The containers were filled with less sediment in this experiment than the previous ones to enhance their depositional characteristics and to reduce the chances of copepods being 'eroded' out of the containers after initial deposition. The accumulation of fine organic material in the containers provides evidence that the containers did act as depositional environments. Since the rate of copepod deposition among different treatment containers at a site should have been approximately equal (note the low variation among replicates in Figs. 1, 2, and 3), differences in abundance at the end of the experiment are likely to be due to differences in the rate of active emigration from the different treatments. An alternative explanation is that the differences observed are due to active selection of the Moderate and High treatments, 
rather than a decrease in the rate of emigration from these treatments compared to the None treatment. Copepods would need to have been able to detect the differences in food level from over $2 \mathrm{~cm}$ away, and to have been able to swim against the water flow if this is true. It is interesting to note the similarity of results of the laboratory study which was conducted under conditions of no-flow where active behaviors had to entirely produce the outcome, and those of the field study which was conducted under natural flow conditions where passive mechanisms were likely also to have been involved. Patterns of abundance for Scottolana canadensis and Zausodes arenicolus, although different from each other, were similar in the laboratory and the field studies.

Chlorophyll a measurement provided only a rough index of food levels available to dispersing copepods. Differences in other factors such as bacterial levels, diatom species composition, and organic content were certainly also present. It would be incorrect to suggest that differences in copepod abundance are due to chlorophyll a levels in the sediment alone. There is evidence from preference experiments that copepods can be extremely selective in choosing areas to settle (Ravenel \& Thistle 1981, Decho \& Castenholz 1986). The strong differences in species composition among the food treatments is likely to be due to the different requirements of individual species. Likewise intraspecific differences in feeding may help explain the difference in behavior by different population components. It has been shown that ontogenetic feeding shifts occur for harpacticoid copepods (Decho \& Fleeger $1988 b$ ). It is possible to speculate that adults might be more selective than copepodites, as seems to be true for Scottolana canadensis in this study (Fig. 8), because of 'learning'. One important implication of these results is that it is not possible to estimate the dispersal tendencies of individual species or population components within species using settling trays with one 'type' of sediment since copepod abundance in the trays will be affected by the specific characteristics of the sediment used.

Selection experiments have recently been conducted for 2 of the abundant species in my study. Zausodes arenicolus often is found in high numbers on macrofaunal fecal mounds (Varon \& Thistle 1988). These authors suggest that this may be a positive response to the particular microbes in the mounds. In my experiments macrofauna were excluded from my treatment containers prior to deployment in the field, perhaps partially explaining why $Z$. arenicolus did not respond to my treatments. In contrast to my laboratory and field results demonstrating that Scottolana canadensis is highly selective for sediment containing high concentrations of food resources, Decho \& Fleger (1988a) observed no tendency for $S$. canadensis to select such sediment in their laboratory and field experiments. The conflicting results of my study and that of Decho \& Fleeger underscore the need for further such studies.

Other factors are known to influence copepod dispersal (see review by Palmer 1988a). For example, harpacticoid density has been shown to affect the rate of active emigration from sediment under controlled conditions of no-flow (Service \& Bell 1987). Certain copepods have also been shown to be positively or negatively influenced in selecting sediment to colonize depending on the presence or absence of other copepod species (Chandler \& Fleeger 1987). The activity of disturbers may influence the rate of entry into the water column (Palmer 1988b). Using closed-circuit television I have observed copepods swimming out of the sediment ahead of a slowly moving probe that I used to mimic the activity of a larger animal (Kern unpubl.). Shifts in behavior by males in response to the relative availability of potential mates (Kern et al. 1984) suggest that the lack of available mates in an area could influence males to disperse in the chance of finding higher concentrations of late copepodite females. Alternatively, Hicks (1988b) hypothesizes that entry into the water column is actually necessary for successful mating].

I have constructed a model incorporating demonstrated and hypothesized influences on copepod dispersal that may depict the relative influences of active and passive mechanisms in a subtidal habitat similar to my study site that is subject to moderate flow conditions (Fig. 10). A copepod in a microhabitat patch continuously evaluates the quality of the patch. If conditions are acceptable in the patch, individuals can act in ways that tend to maintain themselves in the patch by resisting being entrained by flow. Several mechanisms for resisting flow have been described. Some copepods live in tubes (Chandler \& Fleeger 1984) or burrows (Chandler \& Fleeger 1987), have the ability to anchor themselves to sediment grains with adhesive glands (Watkins 1987), or may simply crawl below the sediment surface (Palmer 1984). Alternatively, if population density is too high, food levels too low, potential mates relatively unavailable, or it is otherwise unacceptable, a copepod could swim out of the sediment to be dispersed by currents (Armonies 1988b) or reduce behaviors that tend to help resist being entrained by flow. Once in the water column copepods will largely be passively transported by currents until they are deposited in a new patch which would then become subject to the evaluation process.

The proposed model for my study area is largely supported by the results of my field food-level experiment. The model would predict that emigration rates out of the food-poor containers would be higher than in the more microbially-enriched containers. This is evi- 


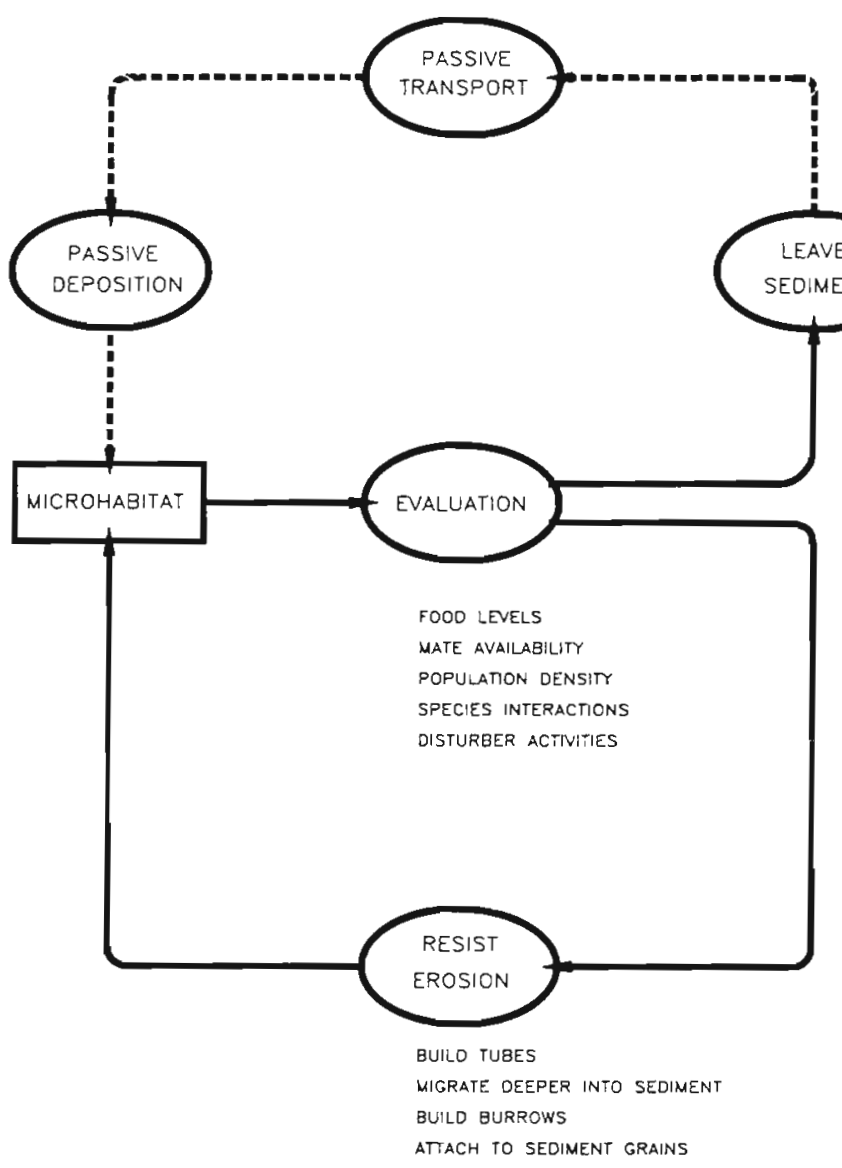

dently what did occur in this experiment. Its applicability to areas with lesser or higher flow conditions needs to be evaluated. The results of selection experiments carried out on a high-energy Oregon beach using an experimental design similar to the one used in the present study (Kern \& Taghon 1986), does suggest that the model might also be applicable in more energetic areas. The beach in Oregon has flow conditions that should produce a predominance by passive mechanisms under Palmer's (1988a) model. This conflict points out the need for further work in a number of different sites to clarify the details of copepod dispersal.

In sum, several lines of evidence are used to support the predominance of active behavior in copepod dispersal in subtidal areas subject to moderate flow conditions. Results of a preference experiment performed in the field show that several copepod species have enhanced settlement in microbially-enriched sediment, mimicking results of a similar experiment performed on a high-energy beach. In a laboratory study conducted under conditions of no-flow, 2 harpacticoid species showed similar patterns of colonization to that which they exhibited in the field. My results support Fegley's (1988) suggestion that meiofaunal behavior is more important than the magnitude of meiofaunal drift in determining net colonization rates. It is possible that
Fig. 10. Proposed model for meiobenthic copepod dispersal at the CCP and PC study sites. (-) active behavior; (--) passive movement

the role of passive processes in meiobenthic copepod dispersal have been over-emphasized in the recent literature and that active behavior is most important in determining copepod dispersal and, ultimately, copepod abundance in the sediment.

Acknowledgements. I thank R. Pupkin and W. Savidge for reviewing and making helpful suggestions on an earlier version of this mauscript; J. Dirnbeger and R. Gouguet for assistance with computers; R. Kalke and F. Fiers for aid in the identification of some copepods; P. Montagna for use of laboratory facilitıes; the Louisiana Department of Wildlife \& Fisheries for access to microscopes and computers.

\section{LITERATURE CITED}

Armonies, W (1988a). Active emergence of meiofauna from intertidal sedment. Mar. Ecol. Prog. Ser 43: 1.51-159

Armonies, W (1988b). Hydrodynamic factors affecting behaviour of intertidal meiobenthos. Ophelia 28: 183-193

Chandler, G. T., Fleeger, J. W. (1983). Meiofaunal colonization of azoic estuarine sediment in Louisiana: mechanisms of dispersal. J. exp. mar. Biol. Ecol. 69: 175-188

Chandler, G. T., Fleeger, J. W. (1984). Tube-building by a mame melobenthic harpacticoid copepod. Mar. Biol. 82: 15-19

Chandler, G. T., Fleeger, J. W. (1987). Facultatıve and inhıbstory interactions among estuarine meiobenthic harpacticoid copepods. Ecology 68: 1906-1919

Decho, A. W., Castenholz, R. W. (1986). Spatial patterns and 
feeding of meiobenthic harpacticoid copepods in relation to resident microbial flora. Hydrobiologia 131: 87-96

Decho, A. W., Fleeger, J. W (1988a). Microscale dispersion of meiobenthic copepods in response to food-resource patchiness. J. exp. mar Biol. Ecol. 118: 229-243

Decho, A. W. Fleeger, J. W (1988b). Ontogenetic feeding shifts in the meiobenthic harpacticoid copepod Nitocra lacustris. Mar Biol. 97: 191-197

Eckman, J. E. (1983). Hydrodynamic processes affecting benthic recruitment. Limnol. Oceanogr 28: 241-257

Fegley, S. R. (1988). A comparison of meiofaunal settlement onto the sediment surface and recolonization of defaunated sandy sediment. J. exp. mar Biol. Ecol. 123: 97-113

Hicks, G. R. F. (1986). Distribution and behavior of meiofaunal copepods inside and outside seagrass beds. Mar. Ecol. Ser. 31. $159-170$

Hicks, G. R. F. (1988a). Sediment rafting: a novel mechanism for the small-scale dispersal of intertidal estuarine meiofauna. Mar Ecol. Prog. Ser. 48: 69-80

Hicks, G. R. F. (1988b). Evolutionary implications of swimming behaviour in meiobenthic copepods. Hydrobiologia 167/168: 497-504

Huys, R., Herman, R. L., Heip, C. (1986). Seasonal flucuatioins in vertical distribution and breeding activity of a subtidal harpacticoid community in the Southern Bight, North Sea. Neth. J. Sea Res. 20: 375-383

Kern, J. C., Bell, S. S. (1984). Short-term temporal variation in population structure of two harpacticoid copepods, Zausodes arenicolus and Paradactylopodia brevicornis. Mar Biol. 84: 53-63

Kern, J. C., Edwards, N. A., Bell, S. S. (1984). Precocious clasping of early copepodite stages: a common occurrence in Zausodes arenicolus Wilson (Copepoda:Harpacticoida). J. crust. Biol. 4: 261-265

This article was presented by Professor S. P. Meyers, Baton

Rouge, Louisiana, USA
Kern, J. C., Taghon, G. L. (1986). Can passive recruitment explain harpacticoid copepod distributions in relation to epibenthic structure? J. exp. Mar Biol. Ecol. 101: 1-23

Palmer, M. A. (1984). Invertebrate drift: behavioral experiments with intertidal meiobenthos. Mar. Behav. Physiol. 10: 235-253

Palmer, M. A. (1988a). Dispersal of marine meiofauna: a review and conceptual model explaining passive transport and active emergence with implications for recruitment. Mar Ecol. Prog. Ser 48: 81-91

Palmer, M. A. (1988b). Epibenthic predators and marine meiofauna: separating predation, disturbance, and hydrodynamic effects. Ecology 69: 1251-1259

Palmer, M. A., Gust, G. (1985). Dispersal of meiofauna in a turbulent tidal creek. J. mar Res. 43: 179-210

Ravenel, W. S., Thistle, D. (1981). The effect of sediment characterustics on the distribution of two subtidal harpacticoid species. J. exp. mar. Biol. Ecol. 50: 289-301

Service, S. K., Bell, S. S. (1987). Density-influenced active dispersal of harpacticoid copepods. J. exp. mar Biol. Ecol. 114: 49-62

Sokal, R. R., Rohlf, F. J. (1981). Biometry. W H. Freeman \& Co., San Francisco

Steel, R. G. D., Torrie, J. H. (1980). Principles and procedures of statistics. McGraw-Hill Book Co., New York

Varon, R. Thistle, D. (1988). Response of a harpacticoid copepod to an small-scale natural disturbance. J. exp. mar. Biol. Ecol. 118: 245-256

Watkins, R. L. (1987). Descriptions of new species of Bradyellopsis and Perisscope (Copepoda:Harpacticoida) from the California coast with revised keys to the genera. J. crust. Biol. 7: 380-393

Wieser, W (1960). Benthic studies in Buzzards Bay. II. The meiofauna. Limnol. Oceanogr. 5: 121-127

Manuscript first received: June 14, 1989

Revised version accepted: October 19, 1989 